\title{
Epitaxy of rhodochrosite $\left(\mathrm{MnCO}_{3}\right)$ on muscovite mica and its relation with calcite $\left(\mathrm{CaCO}_{3}\right)$
}

\author{
Sander J.T. Brugman, Anne B. Ottenbros, Frank Megens, Willem J.P. van \\ Enckevort, and Elias Vlieg* \\ Radboud University, Institute for Molecules and Materials, Heyendaalseweg 135, 6525AJ \\ Nijmegen, The Netherlands \\ E-mail: e.vlieg@science.ru.nl
}




\section{S1. Conoscopy of epitaxial $\mathrm{MnCO}_{3}$ on muscovite mica}

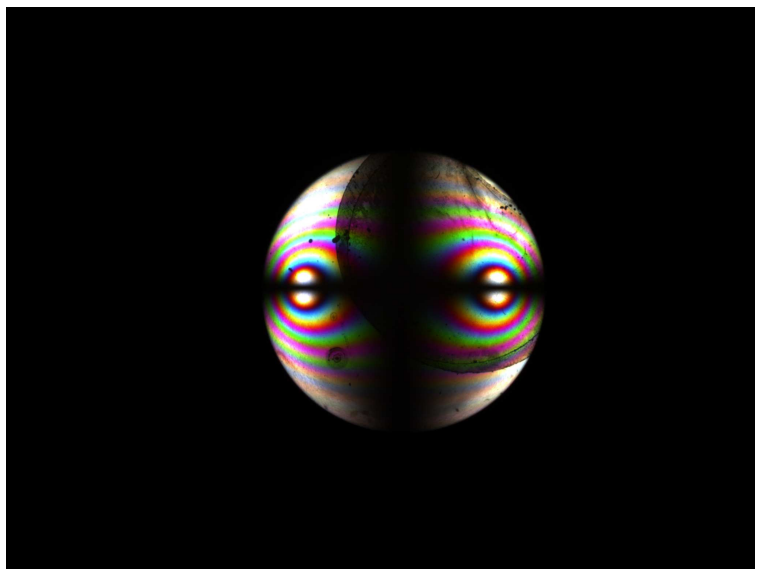

(a)

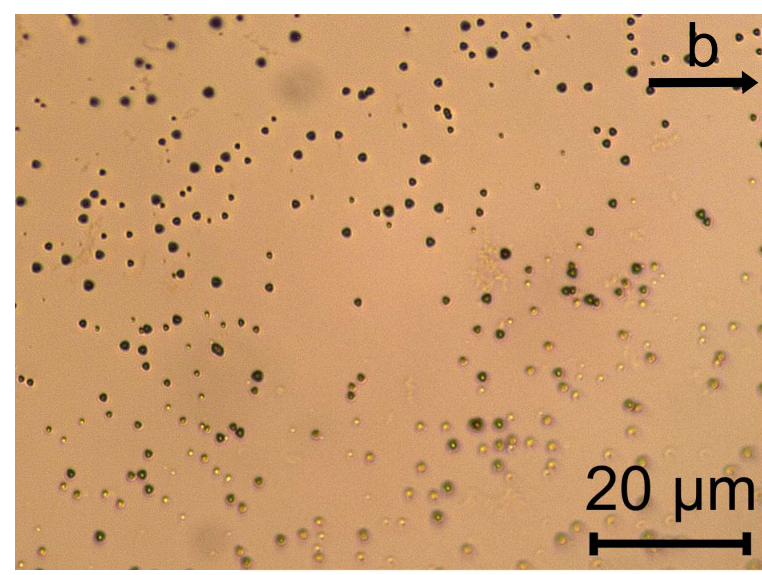

(b)

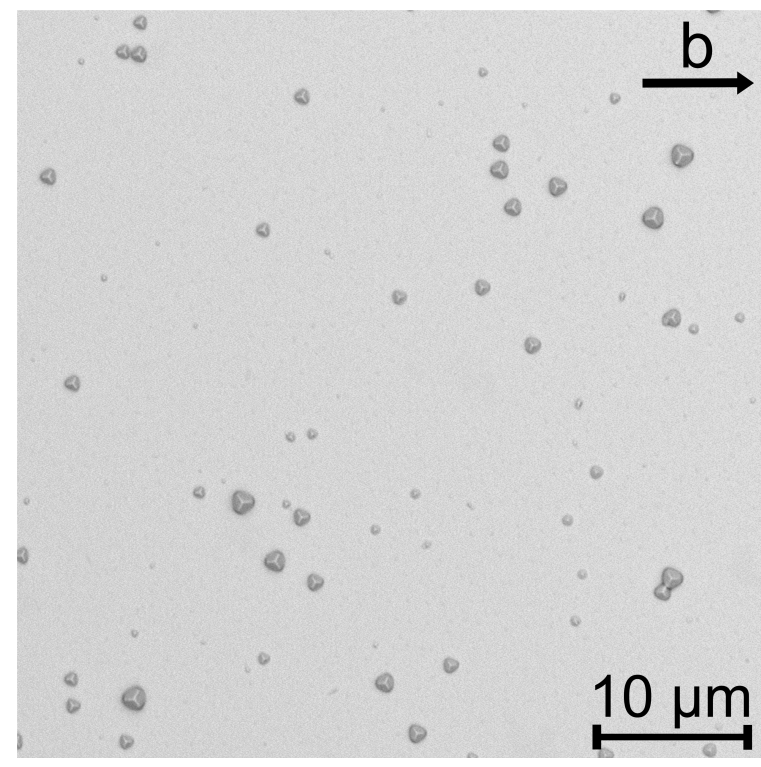

(c)

Figure S1: (a) Conoscopy image of muscovite mica used to determine the muscovite $a$ and $b$ axes. ${ }^{1}$ (b) Corresponding optical microscopy image of the muscovite mica surface with $\mathrm{MnCO}_{3}$ crystals. In this image the muscovite mica $b$-axis lies horizontally and the $a$-axis vertically, as was determined using X-ray diffraction. (c) Scanning electron microscopy image of the same sample and with the same muscovite orientation. The $\mathrm{MnCO}_{3}$ crystals were grown from a $5 \mathrm{mM}$ solution with a crystallisation time of 2 hours. 


\section{S2. Conoscopy of epitaxial $\mathrm{CaCO}_{3}$ on muscovite mica}

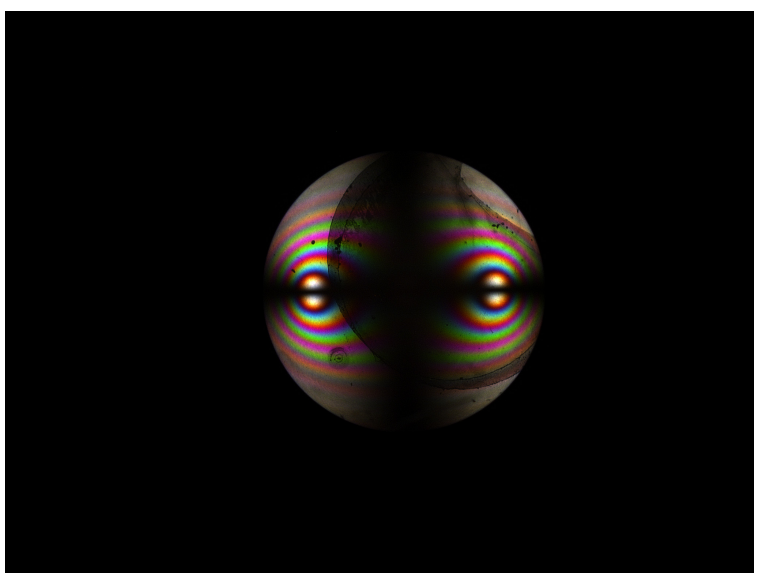

(a)

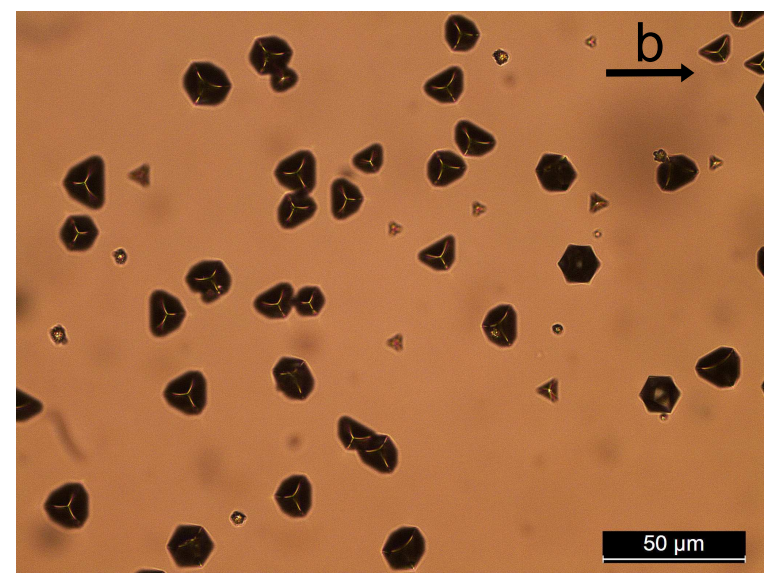

(b)

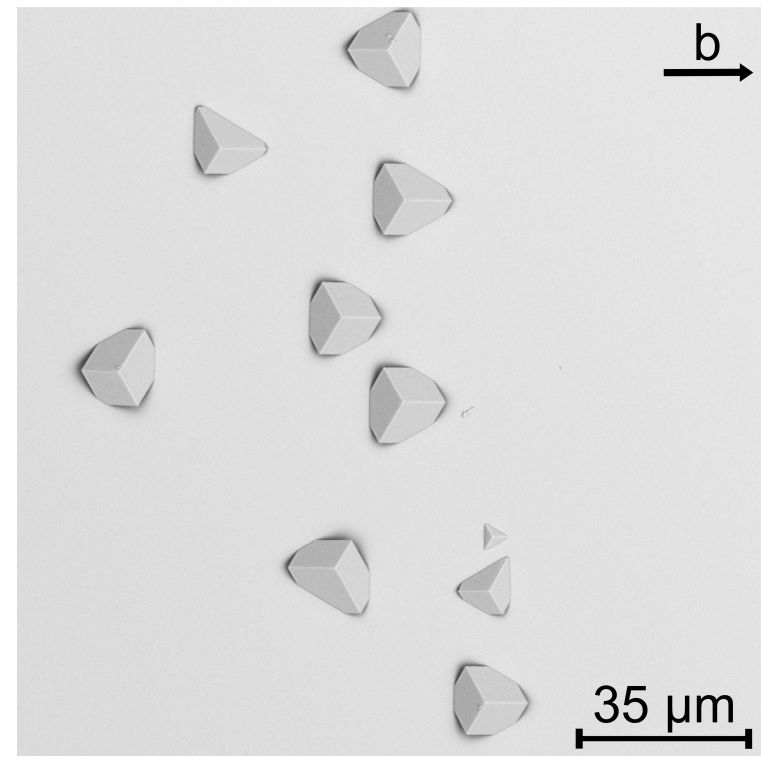

(c)

Figure S2: (a) Conoscopy image of muscovite mica used to determine the muscovite $a$ and $b$ axes. ${ }^{1}$ (b) Corresponding optical microscopy image of the muscovite mica surface with $\mathrm{CaCO}_{3}$ crystals. In this image the muscovite mica $b$-axis lies horizontally and the $a$-axis vertically, as was determined using X-ray diffraction. (c) Scanning electron microscopy image of the same sample and with the same muscovite orientation. The $\mathrm{CaCO}_{3}$ crystals were grown on muscovite which was exposed to $37.5 \%$ relative humidity. For this a $5 \mathrm{mM}$ solution was used with a crystallisation time of 2 hours. The $\mathrm{CaCO}_{3}$ crystals show the same orientation as the $\mathrm{MnCO}_{3}$ crystals shown in Fig. S1. 


\section{S3. Orientation and symmetry of the epitaxial MnCO3 crystals on mica}

To validate the preferred orientation and three-fold symmetry of the epitaxial $\mathrm{MnCO}_{3}$ crystallites on the muscovite mica substrate, the orientation, $\alpha$, of the line-shaped ridges at the intersection of two adjacent $\{104\}$ faces of the $\mathrm{MnCO}_{3}$ crystals are measured with respect to the muscovite mica b-axis (Fig. S3). For this the SEM micrograph displayed in Supporting Information S1 is used. In this figure the orientation of the substrate b-axis is determined by polarisation microscopy. For the two groups of opposite $\mathrm{MnCO}_{3}$ crystallites, A and B in Fig. S3, this yields an average angle, $\alpha$, with respect to the mica b-axis of 3.4, 122.8 and $244.6^{\circ}$ for group A and 184.8, 67.7 and $304.5^{\circ}$ for group B. 9 crystallites (i.e. 27 ridges) of type A and 12 (i.e. 36 ridges) of type B were measured. The standard deviation of these measurements is about $3^{\circ}$, which is close to the error of $2^{\circ}$ for each individual measurement. This shows that the ridges and thus the opposite $\{104\}$ faces point towards the mica b-axis and its trigonal (pseudo) symmetric equivalents, close within the error of the measurements. The three angles between the adjacent ridges are 119.4, 121.8 and $118.8^{\circ}$ for group A and 117.1, 123.2 and $119.7^{\circ}$ for group B. This is close to the theoretical value of $120^{\circ}$ and confirms the trigonal symmetry and thus the $\{001\} \mathrm{MnCO}_{3}$ contact face.

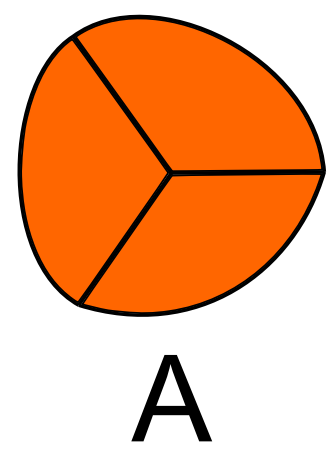

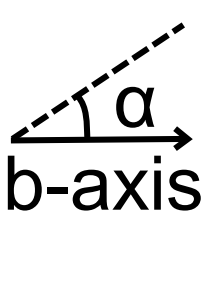

(a)

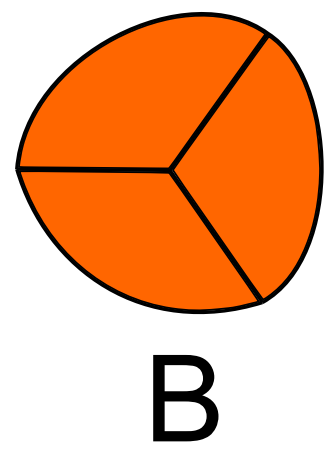

Figure S3: Orientation measurement of the two opposite groups, A and B, of epitaxial $\mathrm{MnCO}_{3}$ crystallites with respect to the muscovite mica substrate. The angle, $\alpha$, between the ridges contacting adjacent $\mathrm{MnCO}_{3}$ $\{104\}$ faces and the b-axis of the mica substrate is used as a measure for orientation. 


\section{S4. SEM image of vaterite}

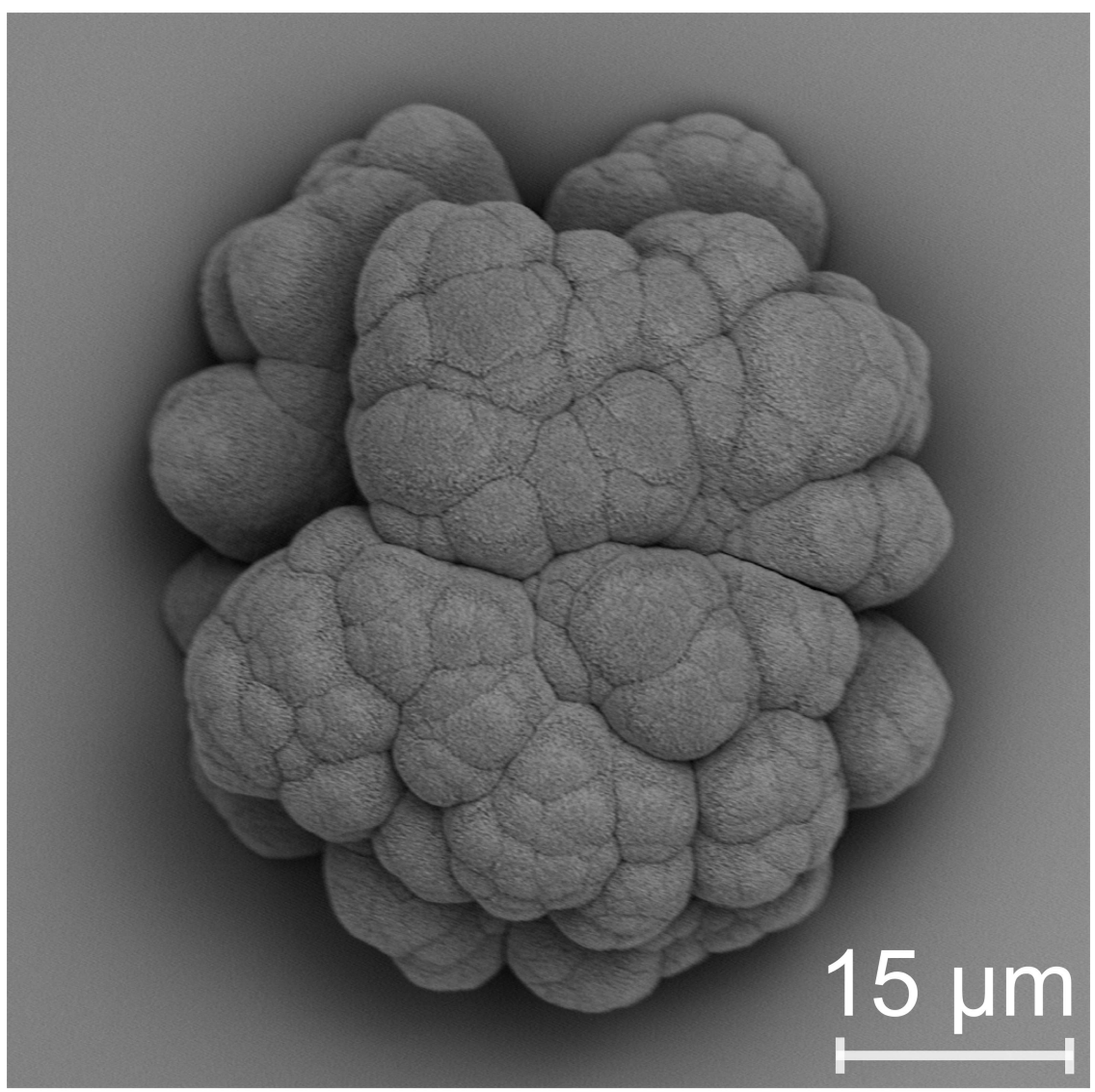

(a)

Figure S4: Scanning electron microscopy image of vaterite grown on muscovite mica. This crystal was grown in a solution with $250 \mathrm{mM} \mathrm{CaCO} 3$ concentration. 


\section{S5. $\mathrm{CaCO}_{3}$ double crystal growth experiment}

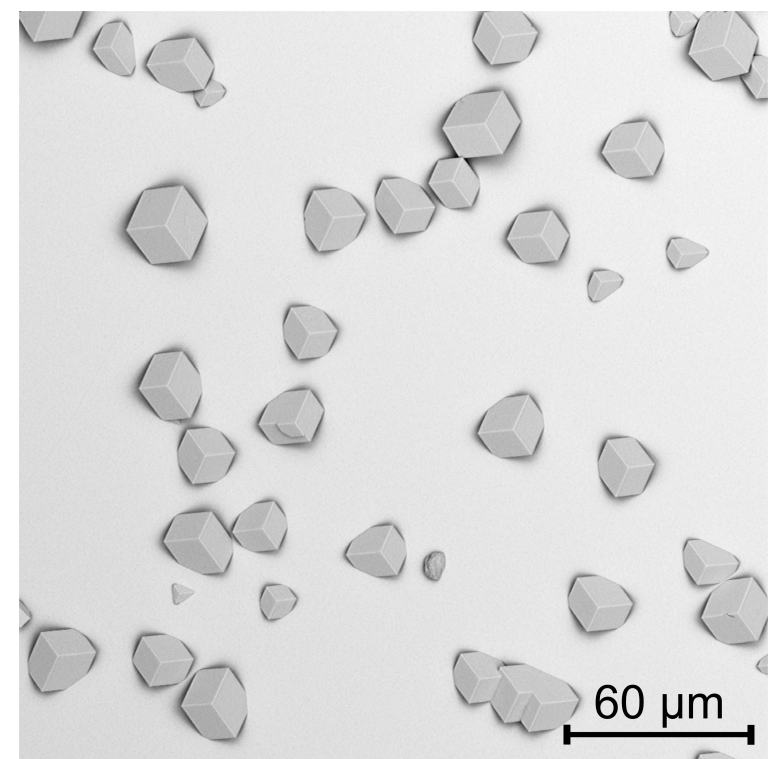

(a)

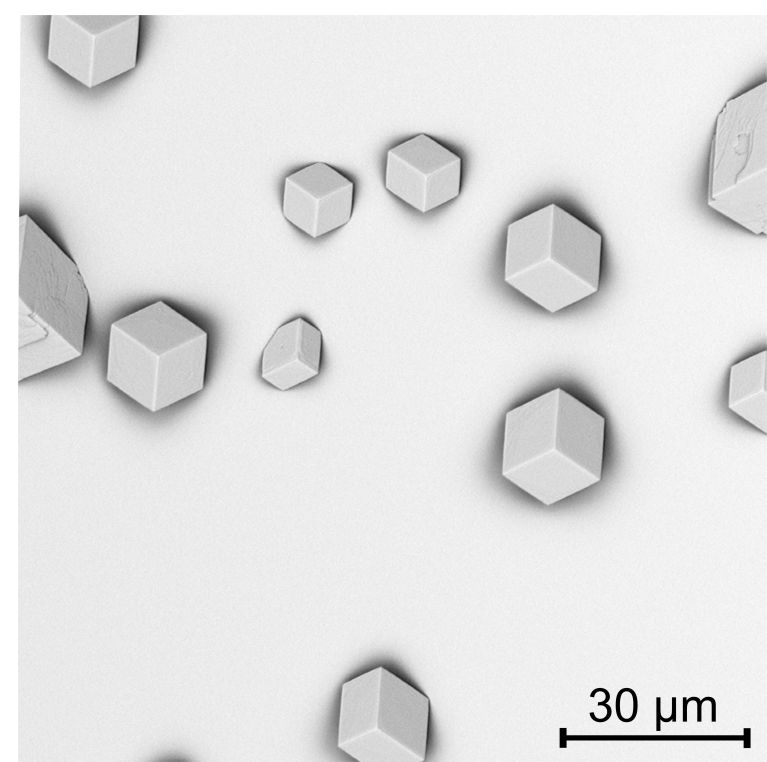

(b)

Figure S5: Scanning electron microscopy images of epitaxial $\mathrm{CaCO}_{3}$ crystals on muscovite mica. Muscovite was exposed to $37.5 \%$ relative humidity ${ }^{2}$ for $1 \mathrm{~h}$ and the subsequent crystal growth experiments of $2 \mathrm{~h}$ were performed twice, similar to $\mathrm{MnCO}_{3}$ (Fig. 5). The experiments were performed with (a) two times 5 $\mathrm{mM} \mathrm{CaCO}$ and (b) two times $50 \mathrm{mM} \mathrm{CaCO}$.

\section{References}

(1) Wahlstrom, E. E. Optical crystallography; John Wiley \& Sons, 1979.

(2) Stephens, C. J.; Mouhamad, Y.; Meldrum, F. C.; Christenson, H. K. Epitaxy of calcite on mica. Cryst. Growth Des. 2010, 10, 734-738. 